\title{
Family medicine in Japan
}

\section{INTRODUCTION}

If you are passionate about primary care then it is always uplifting to meet people who feel the same. The argument for a structured primary care system in Japan has been ongoing for some time but it is only in the last few years that it is gathering momentum. Indeed, from a distance one might wonder why on earth Japan needs to change anything? It has one of the highest life expectancies in the world and has a vaccination coverage that outshines the UK. ${ }^{1}$ It was therefore with great excitement that I set off to meet some the forerunners in the argument for Japanese family medicine.

To visit is to travel simultaneously forwards and backwards in time. This dualism is personified by taking the Shinkansen (bullet train) from Tokyo to the ancient temples of Kyoto. The world of medicine travels along similar lines. In the metropolis of Tokyo there is no shortage of specialist doctors, with investigations and procedures everywhere. If you have a headache, it is acceptable to go and see the neurosurgeon. However, in the more rural parts of Japan it becomes harder to recruit doctors.

Throughout Japan medical care is predominantly free, with a national insurance-based system that requires patients to contribute $30 \%$ of the costs of any medical encounter, although many people have additional insurance through company schemes. However, Japan's ability to continue providing such high levels of hospital-based medicine is facing a considerable challenge. The population is aging while the birth rate is decreasing. In 2002 there were significant problems with the healthcare budget ${ }^{2}$ and suggestions were made to decrease the number of long-term hospital beds from 380000 to $150000 .{ }^{3}$ As the President of the Japan Hospital Association has written:

\section{'We are seeing the phenomenon of an aging society with a falling birthrate, using Japan's financial situation as an excuse in reforms that promote low- spending on medical expenses has caused the quality and safety of medical treatments to drop to very dangerous levels."}

Did anyone shout 'Family medicine to the rescue!'? Despite a reputation for cutting-edge hospital-based interventions, the role of the GP/family physician remains underdeveloped. Some argue that a primary care system, not dissimilar to that found in the UK, needs to be rolled out. Since 2005, members of the RCGP have been visiting Japan to offer advice. Such a

Shinkansen - (bullet train); medicine travels along parallel lines.

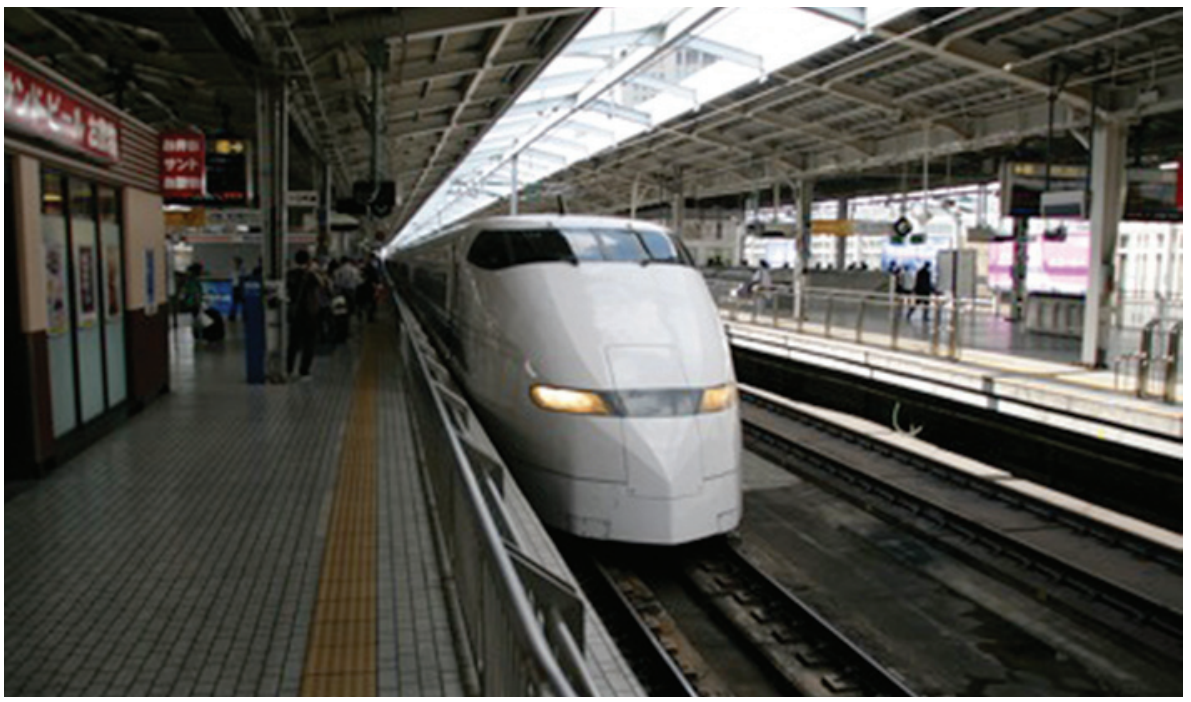

change in emphasis would represent a dramatic break from the past. Before formulating any argument about the need for family medicine one has to define the discipline. In Japan the definitions are multiple.

\section{WHAT IS FAMILY MEDICINE?}

Many people in Japan would argue that family medicine already exists. There are a number of phrases that could be interpreted as representing family medicine ('Sogo-Shinryo', Katei-Iryo', 'Kakaritsuke-I) but all will mean different things, depending on who uses the term. ${ }^{4}$ Often a 'family physician' is someone who runs a clinic with a small number of beds, performing tests such as ultrasounds and endoscopies. More often than not they are hospital specialists without generalist training. Such doctors are some of the highest earners.

No formal training is required to practice family medicine. Those training programmes, which do exist, are not necessarily geared towards communitybased practice. For example, postgraduate training in family medicine might consist of 1 week in a community placement, the rest of the time in hospital settings. The healthcare system allows patients to shop around, accessing specialists directly if they want to. This can lead to conflicting management plans and over-investigation. Despite a national passion for classical music there remains no conductor of the patient's orchestra.

Up until now there are three professional bodies that claim to represent family medicine: the Japanese Academy of Family Medicine, the Japanese Medical Society of Primary Care (with it's subgroup, The Japanese Academy of Primary Care Physicians) and, more recently, The Japanese Society of General Medicine. ${ }^{4}$ In many ways this reflects the divergent complexity of the field. That these three strands plan to merge in 2011 is symbolic. However, the exact nature of the proposed training programmes and issues around certification are still being debated. 


\section{BRINGING ABOUT CHANGE}

Introducing family medicine into Japan is fraught with difficulties. Both the public and the profession associate medicine with high-tech interventions and hospitals. Any attempt to roll out a primary care system is understandably seen as a threat to the hospital doctors. Also making things more complex is that the Japanese Medical Association (JMA) is a large donor to the ruling political party. ${ }^{5}$

The customary bow with which people greet each other provides a clue to the hospital hierarchy; a junior colleague will bow lower than their senior. Doctors are addressed with the coveted term 'Sensei.' There is no age for retirement; many doctors continue to perform procedures well into their eighties. This is an inherently deferential place and represents one of the challenges to trying to bring about any change. Nevertheless, slowly and not so surely, a cluster of family medicine training programmes is starting to spring up around Japan. The Japanese Academy of Family Medicine has now approved 80 training programmes but many would argue that only a small minority of these are fit for purpose.

\section{FUKUSHIMA}

In September 2008 I visited the family medicine training programme set up by Professor Kassai in Fukushima, an industrial and predominantly rural prefecture north of Tokyo. Professor
Kassai trained in paediatrics but became inspired by the idea of family medicine, leaving to spend time in Canada to train with lan McWhinney. It would be fair to say that introducing family medicine to Japan has become something of a life mission.

After establishing his first family medicine training programme in Hokkaido in 2006, Professor Kassai founded the Department of Community and Family Medicine at Fukushima Medical University. This is a rural area where the recruitment of doctors is difficult. The trainees are 16 in number. Scattered across this region Professor Kassai and his two other senior colleagues must travel miles to monitor his trainees, not to mention dashing back and forth to Tokyo to meet a Minister of Health sympathetic to his plans for family medicine, and attending international conferences to raise the profile of his project.

It is hard not to see the trainees as pioneers. From behind a screen I observed one trainee getting through his hospital clinic, time being a constant anxiety. He told me that the nurses didn't really understand him asking about the patient's home, their work, or fears as this all took more time. In short, most trainees are learning their art in a high-tech hospital setting averaging 100 hours a week. While clinics provide a glimpse of the medicine they hope to practice, they still look after a heavy list of acute hospital patients (chemotherapy, acute strokes, Gl bleeds, and administering BIPAP).

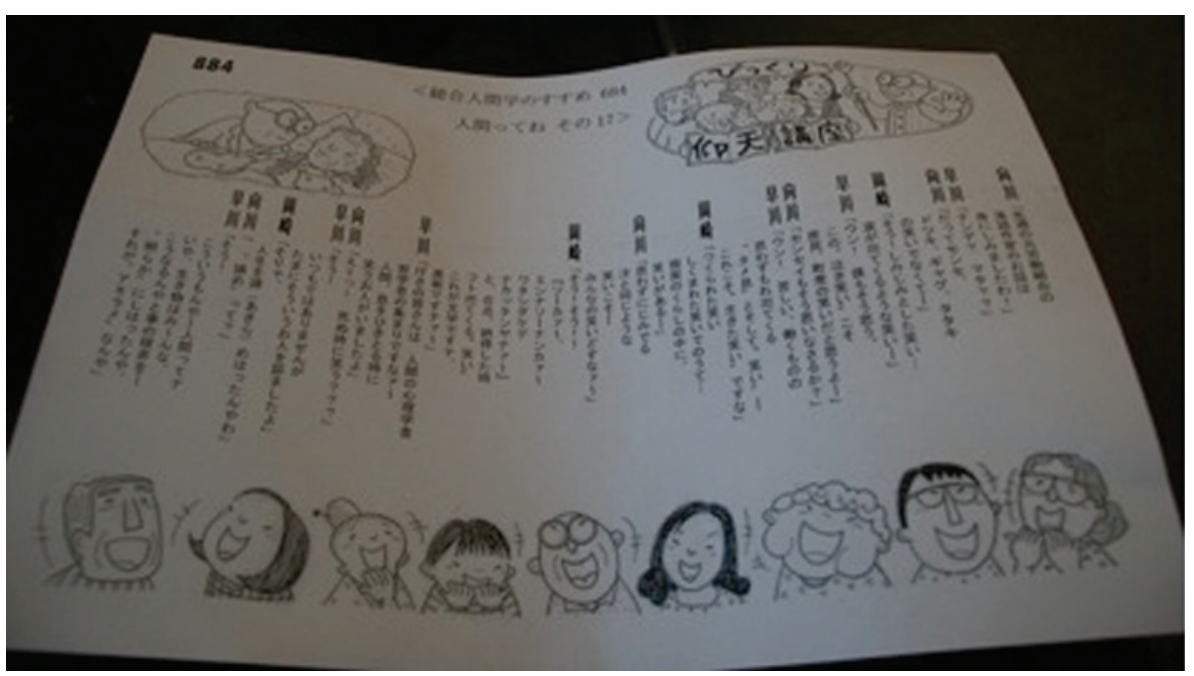

The trainees are united once a week by a teleconference in which they discuss cases and cover clinical topics. Across the board imaging, like most of the technology, is superb. In a community family medicine clinic, where some of the third years students work, I saw patients arrive and return within the hour with their CT imaging.

The trainees are deeply committed to the principles of family medicine, espoused by quoting the likes of lan McWhinney and Roger Neighbour. As soon as these trainees finish they will become the teachers.

\section{SHARED IDEALS}

Professor Kassai's efforts have attracted the attention of doctors with similar ideals.

In the ancient city of Kyoto I met with Doctor Hayakawa. A retired hospital physician, he is deeply committed to looking after the older population. His hospital has set up a system of home visits where the hospital physicians attend patients in their homes. With a respiratory physician I saw a patient who had been on a ventilator for 10 years, and was informed, 'This patient would probably have died of a hospital-acquired infection had they not been at home.'

At 6 am on Saturday mornings Doctor Hayakawa, now in his eighties, continues to hosts his show on Kyoto Radio that he has been running for 20 years. It is dedicated to the older people of the city, highlighting issues that are of concern to them and promoting good health. On the morning I attended, a dietitian explained how to make a healthy bento box for lunch. Less soy was the lesson of the day. The packed studio audience, some who have been to over 100 shows, clap and sings songs. One of these was translated to me as, 'by dancing and singing, we can help stop dementia.'

\section{PARALLEL LINES}

It is hugely tempting to make an analogy with the UK. Sitting in a drinking hall in Tokyo, I spoke to one retired man. He insisted on telling me, as he sipped and bought brandy, that Britain and Japan are so very alike. Both are small islands. Both have a huge history, a royal family, and 
are dependent on the US. In the UK during the 1970s there was an articulation about what general practice was about. Formal training started to arise. One could trace a line bringing us to the present era of oversubscription for GP training posts and the new MRCGP examination.

Is Japan on this tipping point? Perhaps. Although in the 1970s the field of general practice was very much accepted, GPs were the gatekeepers of the NHS. Such foundations do not exist in Japan. The complexities of Japan and its health system means that caution should be advised when trying to draw analogies. Many people could see nothing worse than Japan adopting a UK style health system, as one article heading in the Japanese Hospitals Journal illustrates, 'Healthcare cost containment ruined Great Britain's healthcare system'. ${ }^{6}$

The political boundaries between professional groups may become diluted with time. At the Iwaki Summer Forum for Family Medicine a task was set for the trainees. They were asked: 'What makes a family physician different from a hospital physician?'. In small groups those already on the training programme, along with doctors and medical students interested in family medicine, talked among themselves. The answers came back and were familiar to the patriotism that can be found in the UK: that the family physician was caring, acted holistically, was concerned about the community, and that they didn't over-investigate. One trainee put up their hand up, 'Why aren't all doctors like this?'

From what I saw, the Japanese healthcare system possesses much strength, but there are inevitable weaknesses. Choosing which of these weaknesses to accept is the dilemma of anyone interested in healthcare systems. The portrayal in the medical journals and press, when faced with change, is that there are battles to be fought. Yet these lines usually mean a simplistic understanding of the situation, siphoned down until it is, 'Yes' or 'No.' 'Good' or 'Bad'. It is always far more complicated than this. Professor Kassai is working incredibly hard to try and teach Japan about what family medicine is and how it

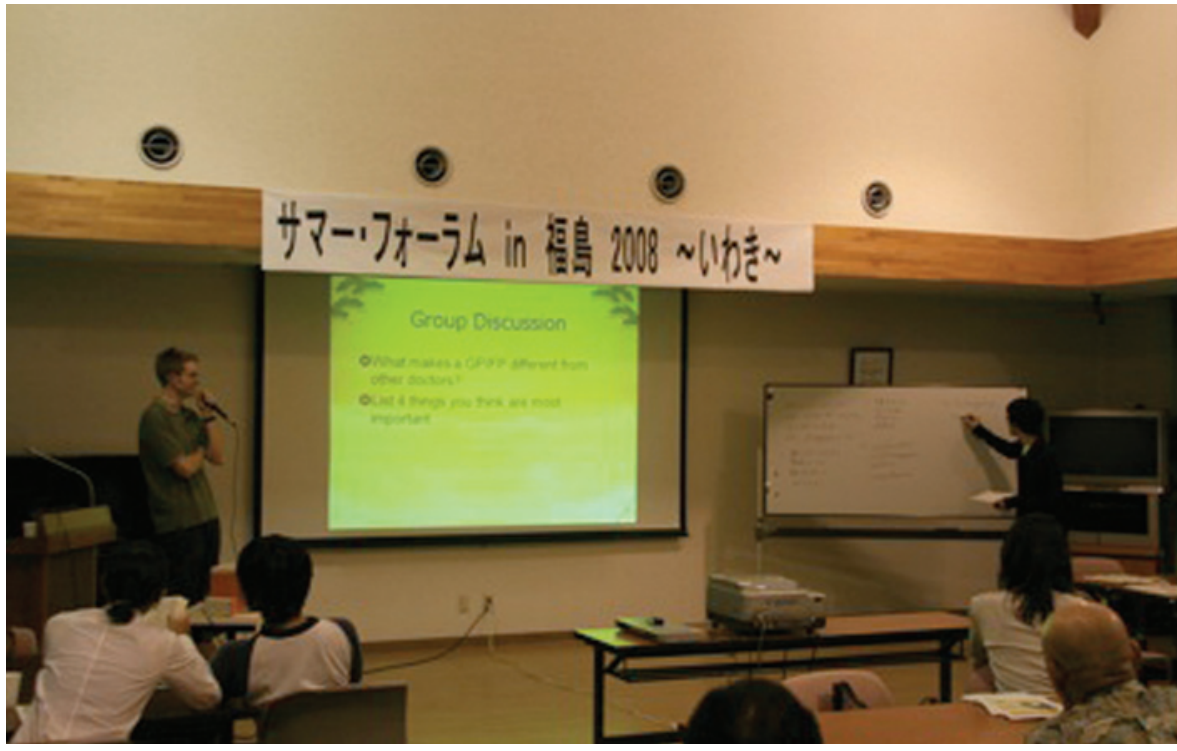

Patrick Hutt running a work shop on general practice at the Iwaki Summer Forum for Family Medicine.

might work. He has even written the first part of a script for a television drama hoping to harness the media channels. Alas, he has not had any luck in getting producers to take up the idea. Family medicine is not as sexy as the high drama of the hospital that saves lives by the minute.

Those who want to be reminded about medicine's potential to act with great compassion could do worse than watch Akira Kurosawa's film Red Beard. Set in the 19th century, it tells the story of a young doctor, arrogant and hot headed, filled with the latest lessons in European medicine, who is tricked into working in an unglamorous impoverished part of Japan. He comes up against the eccentric 'Red Beard' - a doctor who has dedicated his career to this local population. The new recruit mellows with compassion as he sees the necessity to serve the local people. As in A Fortunate Man, ${ }^{7}$ an artist turns the doctors work into poetry.

Ninja; in its original Chinese form, the character 'Nin' means patience. For all those trying to change a medical system, despite the huge frustration that can come from wanting to change something that you believe is wrong, patience is an incredibly valuable asset. All developed countries appear in a state of flux, grappling with questions for which there are no easy answers. How do countries provide for their population?
When the patient is sitting in front of you these questions seem mundane and tedious.

This is what is so fascinating about Japan, to watch this debate unfold without the same proximity to the reality that might ensue. Detachment for GPs when looking at the NHS is hard to achieve when patients are waiting, and the next government directive has arrived. The UK and Japan may be miles apart but the issues faced in both countries are very close to home.

\section{Patrick Hutt}

\section{REFERENCES}

1. World Health Organization. WHO vaccinepreventable diseases: monitoring system 2009 global summary - country profile Japan.

http://www.who.int/vaccines/globalsummary/immun ization/countryprofileresult.cfm (accessed 12 Aug 2009).

2. Yamamoto $S$. At the beginning of a new year. Foreward. Jpn Hosp 2008; (27): 1-2.

3. Nishida Z. Proposal of benchmark to study hospital management sustainability. Jpn Hosp 2008; (27): 3-12.

4. Takemura Y. Family medicine: what does it mean in Japan? Asia Pacific Family Medicine 2003; 2:188-192.

5. Kondo J. The iron triangle of Japan's health care. $B M J$ 2005; 330(7482): 55-56.

6. Kondo K. Beyond the era of cost containment. Jpn Hosp 2008; (27): 19-38.

7. Berger, J, Mohr J. A Fortunate Man: the story of a country doctor. London: Penguin; 1967. 